\title{
ROMAN CHINUA ACHEBEJA RAZPAD KOT ODGOVOR NA NEGATIVNO PREZENTACIJO AFRIČANOV
}

Ključne besede: dekolonizacija, drugi, postkolonialna literatura, esencializacija

Predmet raziskave bo pregled nekaterih praktičnih izhodišč postkolonialne literature. Odgovoriti na vprašanje, kako so se oblikovali stereotipi o Afriki, kaj so bili materialni pogoji skreirane drugosti in kako se je na vse to odzival Chinua Achebe $\mathrm{z}$ romanom Razpad, katerega naslov je povzet po verzu pesmi The Second Coming pesnika W. B. Yeatsa, pomeni spregovoriti o začetkih afriške (in ne samo nigerijske) literature. Negativni reprezentaciji Afričanov, ki je sicer zgodovinsko pogojena in sta jo do potankosti privzela Joseph Conrad v romanu Srce teme in Joyce Cary v romanu Mister Johnson, je sledil sistematičen odgovor. Afriška literatura se je torej razvijala dialektično, glede na evropsko literarno stvarnost, predvsem tisto, ki se je dotikala predstavljanja kolonij, vendar je pri tem zanimivo tudi vprašanje: ali obstaja možnost, da bi evropski pisatelj napisal roman o Nigeriji, ki ga nigerijski študentje ne bi kritizirali, oziroma roman, v katerem si Okcident, če privzamemo izraz Edwarda Saida, ne bi prisvajal Orienta? V tem primeru bi se afriška literatura verjetno razvijala povsem drugače in $v$ drugačnih okoliščinah.

\section{Joseph Conrad: Srce teme (1902)}

Ania Loomba v knjigi Kolonializem/postkolonializem razdela enega zanimivejših stereotipov, ki se tiče analognosti seksualnega in kolonialnega 
odnosa: v ponazoritev navaja gravuro iz poznega 16. stoletja - Vespucci discovering America -, na kateri Vespucci v eni roki drži zastavo, v drugi pa mornarsko šestilo in strmi v Ameriko, golo žensko, napol vzdignjeno iz viseče mreže. Slika naj bi ponazarjala kolonialno paradigmo: ženska, kolonialno telo, obljublja (materialno) zadovoljitev, hkrati pa je pojmovana kot legitimni objekt moške (kolonialčeve) želje. Pri tem je simptomatično, da je evropski avanturist individualiziran, aktiven, medtem ko kolonizirani predstavljajo kontinent v celoti, deželo, naravo, ideje ali skupino $(1998,77)$.

Nekaj podobnega se zgodi tudi pri Conradovem opisu prodiranja $\mathrm{v}$ Srce teme: »Tihotna divjina /.../ se mi je ob vsem tem zdela veličastna in nepremagljiva, kot zlo ali kot resnica, ki potrpežljivo čaka, da premine ta fantastični vdor v njeno vsepričujočnost.« $(1984,42)$ Fanatični prodiralec Marlow ob reki Kongo resda ne ropa slonovine v tolikšni meri kot njegovi kolegi, si pa zato želi podvreči "potrpežljivo« divjino. Iz tabule rase $\mathrm{v}$ njegovem otroštvu se Afrika v imaginarni geografiji spremeni v pokrajino teme. Pri tem ga niti ne moti, da v krajih, ki so bili na zemljevidu bele lise, živijo domačini. In tudi ko se sreča $\mathrm{z}$ njimi, zapolni modul binarne razdelitve: »Na eni strani so Zahodnjaki in na drugi strani arabski Orientalci: prvi so racionalni, miroljubni, liberalni, logični, zmožni držati se pravih vrednot, po naravi niso sumničavi; drugim pa ni vrojeno nič od naštetega." (Said, 1996, 68-69) Če predpostavimo, da so ti drugi namesto Orientalci Afričani, lahko pregledamo vsaj negativni postopek, prek katerega se jih reprezentira. Najprej se jih raztelesi, razosebi: »Pozdravil nas je pravcati izbruh krikov, vrvež črnih udov, množica ploskajočih dlani in topotajočih stopal, pozibavajočih se teles, obračajočih se oči.« $(1984,67)$ Da ta živalska množica ni mogla sproducirati nobene preteklosti in da je zato predzgodovinska, je najbrž tudi samoumevno. In ker Afričani ne bivajo v času, vsaj ne $\mathrm{v}$ smislu preteklosti, prihodnosti in sedanjosti, po vsej verjetnosti tudi nimajo razuma. Nekateri "primerki« so sicer močno izboljšani, toda tudi to, kar so se naučili razumeti, razumejo na svoj, poganski način, ki je seveda neprimerljiv z evropsko mislijo.

Conrad se torej očitno zateče k postopku esencializacije: Afriki in Afričanom odreče možnost razvoja, preobrazbe in človeškega gibanja. Nič nenavadnega ni, da zaide v številne paradokse, saj razmišlja z lastnimi civilizacijskimi pojmi: če ti ljudje nimajo zadržkov, kot jih nimajo hijene v lakoti 
in ga kljub temu ne požro, potem pomeni, da niso živali ali vsaj, da imajo moralo. Toda če imajo moralo, potem niso živali in obratno. Naslednji paradoks je na primer, kako lahko živali povezujemo s posmrtnostjo, kot to stori Marlow, ko gleda umirati enega izmed svojih delavcev na parniku. Glede na njegovo krščansko logiko bi domnevali, da živali nimajo duše. Navsezadnje je za Marlowa najbolj strašljiva misel na njihovo »človečnost prav takšno, kot je naša -, misel na našo daljno sorodnost $s$ tistim divjim in strastnim rjovenjem in besnenjem. Bilo je grdo; surovo; strašno; ostudno.« $(1984,67)$ Zdaj je najbrž že jasno, da je pri Marlowu kljub avtopsiji in dejstvu, da ga divjaki kljub izjemni lakoti navsezadnje niso požrli, prevladala tekstualnost. Knjige oziroma teksti, ki jih je prebral, preden se je soočil z neznanim, grozečim in oddaljenim, so dobili večjo kredibilnost kot dejanskost, ki jo opisuje. Prebrana besedila lahko namreč po Saidovem mnenju ustvarijo ne le vednost, temveč tudi realnost. Sčasoma ta vednost in realnost proizvedeta tradicijo oziroma tisto, čemur Michel Foucault pravi »diskurz «. ${ }^{1}$ Conradov roman Srce teme je torej lep primer teksta, sestavljenega iz že prej obstoječih enot vedenja. Odsotnost individualnosti, časa in logike pri Afričanih so pravzaprav le nekatere kategorije skonstruirane drugosti.

Binarne opozicije teme in svetlobe, civilizacije in divjaštva, ki so pri Conradu povzete iz krščanske mitologije, pa navsezadnje niso ključne le za kreiranje podob o drugem/tujcu, temveč tudi za konstruiranje evropskega »sebe«, navadno belopoltega moškega. Čuvarji teme, kolonialisti uradniki, ki se sicer razglašajo za prinašalce luči, dejansko pa so na poziciji samo zato, ker uspešno prenašajo afriško klimo (ko zbolijo, jih zamenjajo drugi), se v deželi Nikjer obnašajo na specifičen način: »Poškrobljeni ovratniki in srajce $\mathrm{z}$ belimi čipkastimi naborki so bili dokaz trdnosti njegovega značaja. /.../ Poleg tega je strastno ljubil svoje knjige, ki jih je hranil v vzornem redu. Vse drugo v tisti postojanki je bilo v strahotni zmešnjavi /.../.«(1984, 32-33) Koloni so bili torej vse tisto, kar kolonizirani niso bili, ali, kot bi se izrazil Said: »/.../ biti Belec je bila zelo konkretna oblika biti v svetu. Pome-

1 Foucaultova opredelitev, da so vse ideje nadzorovane prek materialnega medija in da to na idejah pušča določen vzorec, ki ga imenuje »diskurz«, je v temelju zaznamovala Saidovo delo Orientalizem (1978). 
nilo je - v kolonijah - govoriti na poseben način, vesti se v skladu s pravili in celo čutiti nekatere stvari, drugih pa ne. Pomenilo je specifične sodbe, vrednotenja, gibe. To je bila oblika avtoritete, kateri naj bi se nebelci in celo sami belci podredili.« $(1996,283)$ Prekoračitev domnevne identitete, tako v primeru Afričanov kot Evropejcev, je potencialno pomenilo postati nor. Kurtz, ki se je poenotil z domačini in tako prestopil mejo med »mano« in »drugimi«, je nazadoval v primitivno stanje, znorel in na koncu umrl. Evropejec torej v Afriki, če se ne drži predvidene meje, razpade, degradira v primitivno stanje. Nič čudnega, da je Chinua Achebe Conrada imel za rasista, njegov roman pa za »zgodbo, v kateri se dvomi o človeškosti Afričanov« $(2003,32)$.

\section{Imperii piše nazaj}

Marxov izrek, zapisan v 18. brumairu Ludvika Bonaparta, ki ga je Said postavil kot uvodni verz svoje knjige Orientalizem: »Sie können sich nicht vertreten, sie mussen vertreten werden. « ${ }^{2}$, je za kolonizirano Afriko veljal do leta 1952. V tistem času je namreč razred nigerijskih študentov na univerzi Ibadan razpravljal o najnovejši knjigi Joycea Caryja, Mister Johnson. Revija Time je 20. oktobra 1952 knjigo označila za »najboljši roman, kdajkoli napisan o Afriki« (Achebe, 2003, 22). Achebe in njegovi sovrstniki na univerzi so glede na okoliščine, da so jih poučevali angleški profesorji iz evropskih in britanskih univerz, dotlej predelali Shakespeara, Miltona, Defoeja, Swifta, Wordswortha, Coleridgea, Keatsa, Tennysona, Housmana, Eliota, Frosta, Joycea, Hemingwaya in Conrada. Zgodilo pa se je, da je eden izmed študentov vstal in presenečenemu učitelju odkrito povedal, da je v celi knjigi užival le v prizoru, ko gospod Rudbeck, britanski uradnik, ubije osrednjega junaka, afriškega tepčka Johnsona. Tega dogodka Achebe sprva ni resno jemal, zdelo se mu je celo, da bi razred moral svoje nestrinjanje subtilneje artikulirati, toda kasneje je prepoznal, da je bil upor odločilnega pomena (Achebe, 2003, 23). Ni šlo toliko za to, katera stran ima prav, angleški uči-

2 »Ne morejo se zastopati, ampak morajo biti zastopani.« - Slov. prevod: MEID, III, CZ, Ljubljana, 1967, str. 563. 
telj, zastopnik metropole, ali skupina nigerijskih študentov, temveč bolj za to, da se je razdelitev sploh zgodila.

Problem Gospoda Johnsona po Achebejevem mnenju, izraženem v zbirki esejev Home and Exile (2003), pravzaprav ni v njegovem dezorientiranem afriškem junaku, ki si opijanjen prepeva: »Anglija je moja dežela. / O, Anglija, moj dom ves na veliki vodi. / Tist kralj Anglije je moj kralj, / najboljši člouk na svetu, njegovo srce je ogromno. /.../.« (2001, 33), temveč v tonu pripovedi, načinu reprezentacije, ki je izrazito sovražen do Afričanov in predvsem do okolja, v katerem se odvija roman:

Fada je običajno domačinsko mesto v zahodnem Sudanu. Nima ne lepote, prijetnosti ali zdravja. Bivališče je podobno lovišču za kunce ali jazbini; in niti ni tako čisto. Gre za pionirsko naselbino, staro pet ali šest stoletij, zgrajeno na svojih lastnih odpadkih; celo brez starodavne privlačnosti. Umazanija in smrad sta povsem nova. Najstarejša zgradba, razen emirovega blatnega zaboja, ni stara niti dvajset let. Sonce in dež uničita vsakršno starodavnost, celo vonj. Toda nima niti svežine. Vse zidove iz blata obglodajo koze; polovica rogoznic $\mathrm{v}$ vsakem poslopju je vedno strohnjenih. Beda in omejenost, absolutni vodili ljubosumnih divjakov, konzervativnih, kot so lahko le divjaki, sta jih zadržali na prvem obroču civilizacije. Ti ljudje ne bi zaznali nikakršnih sprememb, tudi če bi čas skočil petdeset tisoč let nazaj. Živijo kot miši ali podgane v dvorskem podu; vse veličastje in umetniška raznolikost, ideje, učenje in bitke civilizacij gredo mimo njih in si jih niti ne predstavljajo $(2001,136)$.

Strateški položaj, kot bi to imenoval Said, "pozicija avtorja v besedilu glede na orientalski material, o katerem piše« $(1996,34)$, je v Caryjevem primeru izrazito negativen. Zdi se celo, da Cary najame Conradovo množico: »/.../ demonični videz nagih plesalcev, ki se režijo, vreščijo, mrščijo ali pa postopajo z zamaknjenimi, brezčutnimi nečloveškimi obrazi, kot povezane vreče svinjske masti ali prepolni mehurji.« (2001, 138-139) Omenili smo že, da Conrad pri svojem opisovanju Afrike, specifičneje Konga, ni bil izviren; to velja tudi za Caryja.

Achebe v knjigi Home and Exile navaja imeni dveh raziskovalk, Dorothy Hammond in Alte Jablow, ki sta objavili študijo britanskih pisanj o podsaharski Afriki skozi štiri stoletja, od 16. do 20. stoletja. Analizirali sta več 
kot štiristo leposlovnih in neleposlovnih del. Knjiga, naslovljena The Africa That Never Was, pokaže, kako so se mitološke predstave o Afriki spremenile $\mathrm{v}$ tradicijo, iz katere so avtorji vedno znova zajemali gradivo za svoje potopise. Zapis angleškega kapitana o zahodni Afriki iz leta 1561 je zgodnejši primer takšne tradicije; Afričani so zanj:

[...] živalska bitja, ki živijo brez Boga, zakona, religije ... katerih žene so skupne, saj ne poznajo zakonske zveze niti ne spoštujejo devištva ... ki prebivajo v jamah in jazbinah: to so njihove hiše in kačje meso njihova hrana, kot je zapisano pri Pliniju in Diodoru. Ne poznajo govora, temveč le režanje in blebetanje. Obstajajo pa tudi ljudje brez glav, ki imajo oči in usta na prsih. (Achebe, 2003, 27)

Pomembno vprašanje je, zakaj je tovrstno pisanje in variacije nanj ujelo evropsko domišljijo in se celo obdržalo skozi stoletja do danes. Ker je služilo določenim namenom? Leta 1561, ko je John Lok prijadral v zahodno Afriko in jo zavzel $\mathrm{z}$ »ognjem in mečem «, je bilo evropsko trgovanje s sužnji že na obzorju. Najprej so seveda trgovali z zlatom, okoli leta 1700 pa izključno samo še s črnim zlatom. Basil Davidson trdi, da so »Evropejci v tem času Afričane videli le kot nemočne ljudi v okovih in da so to predstavo prenesli na Afriko in države, od koder so prihajali sužnji. Vera v afriško inferiornost je bila tedaj že v polnem razcvetu.« $(1980,29)$ Osemnajsto stoletje Evropejcev ni več le navajalo na spektakel »Afričanov v verigah «, temveč je ponudilo tudi literaturo, ki je spektakel upravičila in razložila. Dorothy Hammond in Alta Jablow trdita, da je bila kontinuiteta z zgodnejšim pisanjem ohranjena, le da je vsebina od "podatkovnih " poročil popotnikov prešla v razlago in vrednotenje. Obnašanja Afričanov in njihovih navad se ni le podcenjevalo, temveč prezentiralo kot negacijo vsega človeškega. Interesi trgovine s sužnji so torej ustvarili tako imenovano literaturo razvrednotenja. Eden najradikalnejših zagovornikov suženjstva je bil, po navedbah Dorothy Hammond in Alte Jablow, na primer Dalzel: »Kakršnokoli zlo že povzroča suženjstvo ... je pravzaprav usmiljenje ... za uboge razvaline, ki ... bi drugače trpele pod klavskim nožem« (Achebe, 2003, 29).

Verjetno ni naključje, da Hegel v knjigi Um $v$ zgodovini v skladu z duhom časa trdi podobno: »Edina bistvena sovisnost, ki so jo črnci imeli in 
jo še imajo z Evropejci, je /sovisnost/ suženjstva. V tej črnci ne vidijo ničesar neprimernega. [...] Kljub temu je njihova usoda skoraj še hujša v lastni deželi, kjer je prav tako navzoča absolutna sužnost.« $(1999,175)$ Tega, da tista prava Afrika, ki označuje celino kot tako (Hegel namreč razlikuje še med Egiptom in Severno Afriko), nima nobenega lastnega zgodovinskega interesa in da $\mathrm{v}$ njej prevladuje čutna surovost, ki je posledica absolutne samovolje Afričanov - če je samovolja absolutum, duh namreč ne more vedeti za nobeno občost, od tod tudi ljudožerstvo -, verjetno niti ni treba več omenjati. Na delu je zopet esencializacija: za Hegla Afrika »ne more pokazati nobenega gibanja in razvoja, kar pa se je v njej morda zgodilo, pripada azijskemu in evropskemu svetu« $(1999,182)$.

Zdaj že ni več dvoma, da je tovrstna nastrojenost proti črnemu prebivalstvu služila upravičevanju suženjstva. Toda svojevrstna »zavest « in senzacionalna zabava se $\mathrm{z}$ ukinitvijo suženjstva $\mathrm{v}$ 19. stoletju nista končali. Fantazme o črncih so se regenerirale celo v 20. stoletje in dosegle najprej Conrada, generacijo kasneje pa Caryja - prvega kot popotnika po Kongu, drugega kot uradnika britanskega imperija v deželi, ki so jo tik po prvi svetovni vojni imenovali Nigerija. Na koncu te dolge in mukotrpne poti srečamo skupino nigerijskih študentov, ki se leta 1952 prvič ne strinja s svojim angleškim učiteljem in protestira proti angleški knjigi o Afričanih. Da je do tega prišlo, so morali biti izpolnjeni vsaj trije pogoji: dejstvo, da se je Gospod Johnson dogajal v Nigeriji in ne v kakšni oddaljeni imaginarni afriški državi. V tistem času se je že vzpostavljala protiimperialistična zavest, katere najvidnejši rezultat je bila osamosvojitev prve afriške države, Gane (če odmislimo Liberijo) leta 1957. Do osamosvojitve Nigerije je prišlo tri leta kasneje. Spoznanje o stoletjih ignorance in navsezadnje tudi o krivdi literature $^{3}$ je torej rezultiralo v knjigi Things Fall Apart (1957, slovenski prevod Okonkvo, 1964), ${ }_{4}^{4}$ ki je sistematičen odgovor na dehumanizacijo Afričanov. Pri tem se sicer odpira še načelno vprašanje - ali obstaja možnost, da bi

3 Achebe o romanu Gospod Johnson med drugim pravi: »Kar je njegova knjiga Gospod Johnson naredila zame, je bilo to, da sem podvomil v predpostavljeno nedolžnost otroških zgodb. Posvetilo se mi je, da je lahko leposlovje resnično ali lažno, čeprav je nedvomno izmišljeno.« $(2003,33)$

4 Leta 2008 je izšla popravljena verzija, in sicer pod naslovom Razpad. Spremno besedilo je napisal in korekture opravil Nikolai Jeffs. 
Cary napisal roman o Nigeriji, ki ga nigerijski študentje ne bi kritizirali? Achebejev odgovor se glasi: malo verjetno. Razlog niti ne tiči v tem, da je Cary Evropejec, temveč v dejstvu, da je sam produkt tradicije, ki je Afriko reprezentirala na negativen način. Najbolj ironično pri vsem tem pa je, da Conrad in Cary po sodbi Dorothy Hammond in Alte Jablow sodita med boljše pisatelje, ki konvencije uporabljajo na inovativen in subtilen način, večina pisateljev, zajetih v knjigo The Africa That Never Was, namreč niti ne ustreza literarnim kriterijem (Achebe, 2003, 40-41).

Leta 1951 je pri londonski založbi Methuen izšla drobna knjižica, naslovljena West Africa, avtorja F. J. Pedlerja. Čeprav knjiga ni osvobojena vseh kolonialističnih predpostavk, je za svoj čas nenavadno napredna: avtor upa na pojav afriške literature, ki jo bodo pisali Afričani sami »in nam /tako/ ponudil/i/ avtentične zgodbe iz življenja /lastnih/ ljudi« (1951, 32). Pedler med drugim analizira dve kratki zgodbi neznanih (afriških) avtorjev, objavljeni leta 1945 na tedanji Zlati obali. Njegove vizije o afriški literaturi so se uresničile že leto kasneje (1952), ko je Nigerijec Amos Tutuola objavil roman The Palm-Wine Drinkard (slovenski prevod: 2008) in z njim odprl možnosti za moderni zahodnoafriški roman. Pivec palmovega vina sicer ni napisan v realističnem slogu, kot je morda upal F. J. Pedler, temveč gre za magično odisejado v pidžinu. ${ }^{5}$ Tutuoli so sledili Cyprian Ekwensi z romanom People of the City, Camara Laye iz Gvineje z romanom L'Enfant noir (slovenski prevod: Crni otrok, 1980), Achebe z romanom Razpad, Mongo Beti (iz Kameruna) z romanom Le pauvre Christ de Bomba, Ferdinand Oyono (prav tako iz Kameruna) z romanom Une Vie de boy ter Cheikh Hamidou Kane iz Senegala $\mathrm{z}$ romanom L'aventure ambiguë. »Nova « literatura, ki se je pojavila $\mathrm{v}$ 50./60. letih 20. stoletja, je obravnavala različne tematike $\mathrm{z}$ različnih gledišč in $\mathrm{v}$ različnih slogih, vsem pa je bila po Achebejevem mnenju skupna nit humanosti, ki je avtorja povezovala $\mathrm{z}$ opisovanim svetom $(2003,49)$.

Odzivi na »zahodnoafriški fenomen« so bili različni. Čeprav je v kolonijah za afriškega potrošnika obstajalo kar nekaj manjših založnikov, ki

5 Pidžin oziroma "gnila angleščina ( rotten English) je mešanica nigerijske pidžinske angleščine, polomljene angleščine in občasnih prebliskov dobre, celo idiomatične angleščine (Jeffs, 2008, 254). Možnosti izražanja v pidžinski angleščini je najtemeljiteje izrabil Tutuolin naslednik Ken Saro-Wiwa, in sicer v romanu Sozaboy (1985, slovenski prevod Soldatko, 2008). 
so pokrivali področje izdajanja religioznih tekstov in šolskih knjig, katerih avtorji so bili povečini Britanci, je Alan Hill z izdajo dva tisoč kopij Achebejevega romana leta 1957 v posebni izdaji African Writers Series sprožil revolucijo. Da bo britanska založniška hiša Heinemann podprla program izdajanja knjig afriških avtorjev in s tem ponudila okrilje ne samo pisateljem, temveč tudi novi generaciji šolarjev v Afriki omogočila, da prvič v zgodovini posežejo namesto po angleških klasikih po domačih avtorjih, ni bilo pričakovati. Achebeju je sledil drugi nigerijski avtor, Cyprian Ekwensi, za njim pa avtobiografija Kennetha Kaunda Zambia Shall Be Free. Angleški pesnik Edward Blishen je African Writers Series upravičeno označil za zbirko, ki je »vzpostavila nov literarni svet« (Achebe, 2003, 51).

\section{Razpad}

Achebejev prvi roman Razpad je torej v prvi vrsti dejanje upora, oblika odgovora kolonialni reprezentaciji Afričanov. Pri tem Achebe ni imel (pozitivnih) literarnih modelov, na katere bi se lahko nanašal, in predhodnikov, s katerimi bi se lahko identificiral. Za svoj roman si je moral najprej izbrati strateško lingvistično in ideološko pozicijo, ki pa se je nanašala na kolonialno tradicijo. Napajal se je torej iz evropskega modela, vendar tako, da ga je v vzpostavljanju afriške literature preobrnil. Napisati afriški roman je pomenilo preseči »objektivnost « kolonialnega diskurz in si v spomin priklicati zgodovino in kulturo etnične skupine Igbo, ${ }^{6}$ skoncentrirane pretežno na jugovzhodu Nigerije. Achebe je to komentiral takole: »Prva knjiga, Things Fall Apart, je bila dejanje pomiritve z mojo preteklostjo.« $(1975,2)$ Vendar pa ritualna vrnitev v preteklost ne napoveduje podobnosti ali celo pripadnosti gibanju negritude, češ da Achebe portretira tragični moment v zgodovini lastnega ljudstva; roman namreč razvije eksplicitne tehnike, s katerimi se upira kolonialni reprezentaciji. Predstavitev junaka v sovisju z

6 Nigerija ima sicer izjemno heterogeno družbo, ki jo sestavlja nekje med 51 in 619 različnih etničnih skupin (Jeffs, 2008, 232). Od neodvisnosti leta 1960 dalje politiko države monopolizirajo vladajoče elite treh največjih etničnih skupin: Igbojev na jugovzhodu, Joruba na jugozahodu in Hausa-Fulanijev na severu. Ostale etnične skupine tvorijo tako imenovane »manjšine«. 
okolico in časom bi realistični roman imel za nekaj povsem samoumevnega, toda če uvodni odlomek, v katerem je Okonkvo prikazan v dramatični situaciji, beremo v širšem kontekstu, kot vis-à-vis kolonialnemu diskurzu, pridobi drugačen pomen. Na Okonkvo predvsem ni nič eksotičnega; Achebe svoj lik »naturalizira «, postavi ga v univerzalni kontekst, kar kaže na njegovo strateško odločitev: odmakniti se od fantazem, ki se jih je v kolonialni dikciji in retoriki projiciralo v Afriko. Toda da bi sploh razumeli Achebejevem narativne tehnike, moramo najprej pregledati, kako je kolonializem reprezentira Afriko. Afrika je bila ne samo pri Conradu ali Carju, temveč tudi v antropoloških ali vladnih zapisih predstavljena kot "pokrajina brez ljudi« (Caroll, 1970, 16). Afričani namreč nimajo osebnosti. Druga stvar, ki se ji jo odreka, je občutek za zgodovinsko: slavni britanski zgodovinar Margery Perham je na primer trdil, da Igboji ali pripadniki drugih etničnih skupin, živeči na jugovzhodnem delu Nigerije, "pred prihodom Evropejcev niso imeli zgodovine« (Isichei, 1973, 18). Najpomembnejše pa je, da ti »neljudje« ne poznajo pisave in se torej sploh ne morejo predstavljati. Odsotnost pisane besede pomeni odsotnost logike - celo do te mere, da Afričanov niti sami kolonialni raziskovalci ne razumejo.

Razumljivo je torej, da odsotnost osebnostnih lastnosti, zgodovinskosti in razuma postane konstitutivni element Achebejevega romana. Antiroman ali roman, ki "piše nazaj «, generira iste manjkajoče elemente afriškega lika. Okonkvo je na primer že v uvodnem odlomku postavljen v kulturni in časovni kontekst, on sam pa je predstavljen kot heroj z izrednimi sposobnostmi. Slava o njem, ki se razlega daleč naokoli, je vendarle prostorsko zamejena, kar posledično kaže na to, da Igboji prepoznavajo svoje meje, da vedo za svoje specifično mesto v svetu. Izkušnja prostora je tesno povezana $\mathrm{z}$ izkušnjo časa; Okonkvova zmaga v rokoborbi, ki je mimogrede tudi aluzija na zgodbo o Jakobovem boju z angelom v Stari zavezi (Irele, 2001, 122), še posebej če Okonkvo poistovetimo z ustanoviteljem vasi, prikliče tudi zgodovinski spomin. Achebe invocira časovno dimenzijo ne samo, da bi pokazal, da so Umuofijanci ljudje s preteklostjo, temveč na ta način sproži vprašanje izvora, ki se dotika igbojevske identitete. Izvorna kultura med

7 Izraz aludira na knjigo avtorjev Billa Aschrofta, Garetha Griffithsa in Helen Tiffin The Empire Writes Back. Theory and practice in post-colonial literatures (1989). 
drugim pogojuje koherentni sistem simbolov. Življenje igbojevskega ljudstva sledi določenim ritualom in rutini. Ritem kolektivnega življenja je na primer povzet v stavku: »Tako so minevale polne lune in letni časi.« (1964, 45) Vsi neskončni obredi, ki regulirajo življenje, so funkcionalni in omogočajo preživetje skupnosti, hkrati pa obredno sosledje, vsaj v prvem poglavju, daje romanu narativno shemo in sočasno zagotavlja izkušnjo časa. Družba je koherentna, ker ji to omogoča preživetje, toda produktivnost ni mogoča $\mathrm{v}$ času kot statični kategoriji ali, kot bi se izrazil Kwasi Wiredu v eseju How not to compare African traditional thought with Western thought: »Princip racionalnega v mišljenju tradicionalnega Afričana ni povsem odsoten." $(1980,42)$ Nobena družba namreč ni zmožna preživeti brez razumskega znanja o naravnih pojavih, zemlji, času sejanja itd. Navsezadnje pri Achebejevem romanu morda niti ne gre toliko za invokacijo preteklosti kot bolj za diskurz o naravi zgodovine in njenem pomenu za ljudi (Gikandi 1991, 29). Časovno determiniranost romana razkrivajo tudi preskoki: čeprav se roman odpre kot opisovanje sedanjosti, v naslednjem trenutku zaide $\mathrm{v}$ preteklost, prestopimo na primer v čas, ko je bilo Okonkvo osemnajst let, do nastanka Umuofie in spet nazaj v sedanjost. Vzporednice med preteklostjo in sedanjostjo so prisotne tudi kasneje v romanu: »Odtlej je minilo mnogo let, dvajset ali več, in v tem času se je Okonkvova slava raznesla kot požar v grmovju, ki ga razpihuje harmatan.« $(1964,7)$

Ni se torej težko strinjati s trditvijo V. Y. Mudimbe, da je roman Okonkvo pripoved o skupnosti, kjer »vsi govorijo od nekod, kar vedno preklicuje zgodovinskost, nastanek in vprašanja o tem « $(1988,316)$. Umuofia potemtakem tudi ne more biti organsko nespremenljiva skupnost. S samozadostnostjo vedno konfrontirata časovna in prostorska progresivnost. Čas frustriran tudi sam lik in še več, čas onemogoča naravni red stvari in celo ogroža življenje skupnosti ali posameznih ljudi. »Leto, ko si je Okonkvo sposodil pri Nvakibiu osemnajst jamovih gomoljev, je bilo najslabše, kar so jih pomnili. Nič se ni zgodilo ob svojem času, kvečjemu prezgodaj ali prepozno.« $(1964,22)$ Čeprav čas nakazuje zgodovinskost Umuofie, ne gre vedno za pozitiven proces. V drugem poglavju, ko je Okonkvo zaradi naključnega uboja izgnan v materino vas, čas zanika glavnega junaka. V Umuofii si je Okonkvo identiteto izoblikoval tako, da je obvladal čas, v izgnanstvu pa postane dezorientiran, izgubljen v času. In tudi medtem ko je 
odsoten, se vas bistveno spremeni: »Sedem let je pomenilo dolgo razdobje za človeka, ki je živel daleč od svojega plemena. Položaj moža v plemenu je bil spremenljiv.« $(1964,133)$ Iz te perspektive torej niti ni pretirano trditi, da so Okonkvovo tragedijo povzročile časovno in zgodovinsko pogojene družbene spremembe. Glede na to, da je Conrad Afriko predstavljal kot »deželo večnega otroštva«, kot prostor, ki je ujet v preteklost ali statično sedanjost, je razumljivo tudi Achebejevo vztrajanje na časovni dimenziji romana. Roman Okonkvo je sicer več kot le oblika protikolonialnega upora; vsebuje tudi pomembne vsebine afriške eksistence. Alegorična pomembnost Okonkvovega lika je namreč v tem, da ne gre le za romanesknega junaka, temveč za prezenčno figuro afriške zgodovine, ali, kot je to komentiral Achebe skorajda štirideset let po izdaji romana: »Zgodba o Okonkvu je skorajda neizogibna; če ne bi jaz pisal o njem, bi zagotovo kdo drug, saj gre za sam začetek naše zgodbe.« (Irele, 2001, 120)

\section{Ženski princip v romanu}

Flora Nwapa, nigerijska pisateljica, ki pripada isti generaciji kot Achebe in prihaja celo iz istega predela Nigerije, je v zbirki intervjujev z ženskimi afriškimi pisateljicami roman Razpad komentirala: »Gre za delo, ki nas je vse inspiriralo.« $(1990,116)$ Vrednost Achebejevega romana je v dejstvu, da je $z$ invokacijo igbojevske kulture preobrnil kolonialistično razumevanje Afričanov kot inferiornih, toda če je roman Razpad nekakšna replika na Fanonov teoretični tekst Upor prekletih (1961, slovenski prevod že 1963), po Ngugijevem mnenju naj bi bili pravzaprav vsi romani, napisani v šestdesetih, le praktični komentar k Fanonu, in če Fanon navkljub izpraševanju rasnih hierarhij obnavlja obstoječe spolne strukture, potem je tudi Achebejeva ženska marginalizirane. Fanon je sicer s psihoanalitično utemeljitvijo odnosa kolon : koloniziranec delno razbil svojo spolno slepoto: v patriarhalni družbi so ženske razcepljeni subjekti, ki so nenehno opazovani. Postanejo objekti, saj je feminilnost nekaj, o čemer odločajo moški; na enak način poteka popredmetenje črncev. Gre za to, da se vzorec nasilnega obnašanja kolonov nad koloniziranimi prenese na afriške ženske oziroma da je kolonializem intenziviral patriarhalne odnose: domačini, moški, izločeni 
iz javnega življenja, so izvajali tiranijo nad ženskami. Koloni in kolonizirani so si torej delili podoben odnos do Afričank, od tod navsezadnje tudi trditev, da so bile črnke dvojno kolonizirane (Holst Peterson in Rutherford sta na primer leta 1988 izdala delo s pomenljivim naslovom A Double Colonisation, ki opisuje položaj žensk v kolonialni družbi).

Ne glede na to, da Razpad tematsko obravnava predkolonialne družbo ob njenem prvem stiku z belci, je roman predvsem nacionalno dejanje, ali, kot bi se izrazil Ernest Renan v eseju What is a Nation? iz leta 1882, »[...] predniki so nas naredili za to, kar smo. Heroična preteklost, odlični možje, slava ... to je družbeni kapital, na katerem se gradi nacionalna ideja." (Loomba, 1998, 195) Achebejeva zgodnejša romana, drugi roman No Longer At Ease je sledil leta 1960, sta nastala pred osamosvojitvijo Nigerije in $\mathrm{v}$ obeh je prisotna ideja nacionalnega boja, ki naj bi potrdila človeškost, moškost koloniziranih. ${ }^{8}$ Tovrsten odnos ali celo Ojdipov kompleks je še posebej značilen za pisatelje gibanja negritude, med katerimi se je pogosto pojavljala ideja bojevnika, ki naj bi osvobodil žensko Afriko. Vloga, ki ji je pripadala, je bila izključno vloga matere ali ljubimke. Najbolj problematično pri tem pa je, da je podoba ženske (kot kontinenta) privzeta iz Stradanusove slike iz 16. stoletja, na kateri se gola Amerika, napol vzdignjena iz viseče mreže, ozira za oblečenim Vespuccijem, ki jo je prebudil: in odkril. Razlika je le v tem, da imamo tokrat temnopolte akterje; afriški Vespucci se kot človeški subjekt lahko definira le tako, da preneha biti eno s svojim kontinentom, da se odpove svoji ženski naravi, lastnosti, ki ga je opredeljevala kot inferiornega. Achebejev roman sicer ni osamljen primer, podobni nacionalno obremenjeni (moški) liki so se pojavili še pri Ngugiju, in sicer v romanu A Grain of Wheat (1967), Awoonorju, This Earth, My Brother ... (1971), Armahu, The Healers (1975) in Soyinki, Season of Anomy (1973).

8 V romanu, ki je nastal po osamosvojitvi Nigerije, Arrow of God (1964, slovenski prevod Božja puščica, 1977) konflikt med moškim in ženskim principom izgine oziroma je vloga žensk potisnjena še bolj v ozadje; Mati Afrika v konceptu naroda ni več pomembna, neodvisnost je dosežena. Kar zdaj zanima Achebeja, je vodstvo, avtoriteta in integriteta v neodvisni Nigeriji. Na žensko vprašanje se zopet osredotoči v romanu A Man of the People (1966). Ženska tu postane predvsem potencialna volilka, pripadnica naroda, čeprav še vedno ni individualizirana; njena vloga v osnovi ostaja metaforična. 
V Okonkvu je kot utelešenje fizične moči, narodni heroj, determiniran $\mathrm{z}$ ženskim principom. Ženski princip kot eden izmed glavnih elementov romana proizvaja tudi ironijo. Ko na primer Čielo, svečenica boginje Zemlje, odnese Ezinmo, si ji Okonkvo, veliki bojevnik, ne upa nasprotovati: „Varuj se, Okonkvo! Varuj se pogovora z Agbalo. Mar govori človek, kadar govore bogovi? Varuj se!« $(1964,79)$ Čielo je pravzaprav edina, ki lahko utiša Okonkvo; s tem ko deklico odnese v svojo votlino, jo vrne ženskemu svetu, iz katerega jo je poskušal iztrgati Okonkvo, ko je vanjo projiciral svoje želje: »Ko bi bila Ezinma deček, si ne bi delal skrbi. Srce ima na pravem mestu.« $(1964,53)$ Epizoda s Čielo je torej nekakšna reafirmacija ženskega principa. Da ženske v skupnosti igrajo izredno pomembno vlogo, je razvidno še iz drugih primerov: sosednja plemena se v boj z Umuofio ne spuščajo zlahka, saj je znana po svojih bojevnikih in čarovništvu: »Dejavna sila tega uroka je bila enonoga starka. Urok se je v resnici imenoval tudi agadi-nvaji ali »starka««. $(1964,14)$; tudi jam je sicer simbol moškosti, toda brez boginje Zemlje njegova rast sploh ni mogoča. Ženska v Achebejevem zgodnejšem romanu ima torej simbolično, metaforično funkcijo, predstavljena je kot mati zemlja, medtem ko so moški liki individualizirani.

Kljub sugestiji, da je moško-ženska dialektika potrebna za preživetje skupnosti, Okonkvo prisotnost ženskega ves čas vztrajno zanika. Ikemefuno na primer vzljubi, vendar le na skrivaj. »Okonkvo ni nikdar kazal čustev, izvzemi v jezi. Nežnost je pomenila slabost, mož sme kazati samo moč.« $(1964,25)$ Tudi v trenutku, ko zabode Ikemefuno, je Okonkvo prestrašen. »Bal se je, da bi ga imeli za strahopetca.« $(1964,49)$ Po mnenju nekaterih teoretikov (Irele, 2001, 133) naj bi Ikemefunov umor pomenil osrednjo epizodo v romanu, in sicer zaradi zmedenosti, ki jo ob tem občuti Okonkvo, in sovraštva, ki ga po Ikemefunovem umoru začuti Nvoje, Okonkvov sin. $»$ V njem se je nekaj pretrgalo.« $(1964,50)$ Togost pravil skupnosti, kot je Ikemefunovo žrtvovanje ali puščanje dvojčkov v gozdu, Nvoja potegne v krščanstvo. Nvoje se celo preimenuje v Izaka, kar apelira na biblično zgodbo o Abrahamu, ki je namesto sina žrtvoval žival. Adaptacija krščanskega imena pokaže na simbolični obrat Ikemefunovega umora; Nvoje zapusti stare bogove, ki so terjali žrtveno kri in zaključi družinsko zgodovino. Nova religija obljublja novo senzibilnosti, tako kot Zlobni gozd sčasoma pridobi pozitivni pomen, postane prostor, na katerem se vzpostavi nov družbeni 
red, krščanstvo. Okonkvo je torej po eni strani determiniran s pomehkuženim očetom Unoko ${ }^{9}$ in po drugi s sinom, vse tri generacije pa delujejo odbojno. Okonkvo se kot vmesno nihalo ves čas romana bori z osnovnim principom predhodne in prihodnje generacije: ženskim principom, ki ga je Achebe do popolnosti realiziral šele v svojem zadnjem romanu, Mravljišča $v$ savani (1987).

Korekcijo Achebejevega predstavljanja žensk so opravile številne pisateljice, med njimi Flora Nwapa, Ama Ata Aidoo, Buchi Emecheta, Mariama $\mathrm{Ba}$ in Mabel Segun. Posebno spregledana je zadnja od naštetih avtoric, ki je že leta 1953, torej štiri leta pred Achebejevem romanom, napisala kratko zgodbo The Surrender, v kateri problematizira zapostavljenost ženskega »subalternega subjekta «. ${ }^{10}$ Medtem ko je študentom na univerzi Ibadan dana možnost svobodnega izražanja in protestiranja, je za študentke še vedno nenavadno, če se udeležujejo javnih razprav ali se ukvarjajo s športom. Keke, osrednja junakinja, nacionalizem občuti le kot svojevrstno obliko represije: »Svoboda za kaj? Za zatiranje drugih? [...] Dobrodelnost se začne doma! Emancipirajte najprej svoje ženske!« (1995, 4-6). Podobno Flora Nwapa, Achebejeva sovrstnica in "prva " nigerijska avtorica, v središče svojega zanimanja postavlja ženske. O njih piše kot o aktivnih likih in ne kot o metaforičnih objektih nacionalnega boja. Če imajo Achebejeve ženske ponavadi vlogo matere ali ljubimke, Nwapini moški obstajajo kot možje, sinovi ali ljubimci. In če je Achebe pokazal na samozadostnost igbojevskega sveta, ki je zmožen obstajati brez evropskih posegov, so tudi Nwapine ženske zmožne samostojnega življenja. Domet njihovih dejavnosti je izrazito razširjen: poleg materinske in partnerske vloge sejejo, zdravijo in pre-

9 Sinova dejanja postanejo popolno nasprotje očetovih vrednot, čeprav to še ne pomeni, da Okonkvo zanika vse estetske in človeške lastnosti, povezane z očetom. Odpove se sicer umetnosti besede in s tem postane marginalen v lastni družbi, toda $v$ svoji notranjosti je še vedno občutljiv. Problematično je, da nežnejših čustev ne more javno izraziti, ne da bi bil pri tem izenačen $\mathrm{z}$ očetom. Okonkvo torej med drugim propade tudi zato, ker zanika svojo žensko plat, ki naj bi bila pomemben sestavni del igbojevske kulture. S tem ko potlači podobe, ki ga spominjajo na očeta, se odreže tudi od nezavednega v lastni kulturi (Gikandi 1991, 40).

10 Termin »subaltern « pomeni nižjega ranga, uvedel pa ga je Antonio Gramsci za tiste skupine v družbi, ki so podrejene hegemoniji vladajočih razredov. Indijska kritičarka Gayatri Chakravorty v svojem eseju Can the Subaltern Speak? iz leta 1985 trdi, da prostor, iz katerega bi "subaltern« lahko spregovoril, ne obstaja. 
prodajajo. Strukturo njihovega življenja nič več ne narekujejo lunine mene, temveč tržni dnevi. Ženskim »subalternom « je torej v nasprotju s trditvijo G. Spivak dan glas, možnost odzivanja na moško avtonomijo, čeprav pisanja ženskih afriških pisateljic ne smemo enoglasno uvrstiti $\mathrm{v}$ feministično gibanje. Vse navedene pisateljice bi nam namreč zatrdile, da je zahodni feminizem spregledal rasna in kolonialna vprašanja ter da so se zahodne feministke - v imenu svojih nemih vrstnic, ki so jih predstavljale - legitimirale kot imperialne avtoritete. Toda to vprašanje odpira že nove teme, ki niso predmet te razprave.

\section{LITERATURA}

Achebe, Chinua: Okonkvo. Prevedel Branko Avsenak. Založba Obzorja Maribor, Ljubljana 1964.

Achebe, Chinua: A Man of The People. Heinemann Educational Books, London 1966.

Achebe, Chinua: The Novelist as Teacher. V: Walsh, William: Readings in Commonwealth Literature, Oxford 1973, Clarendon Press. 181-185.

Achebe, Chinua: Morning Yet on Creation Day: Essays. Heinemann, London 1975.

Achebe, Chinua: Božja puščica. Prevedla Alenka Moder Saje. Pomurska založba (Zbirka Mostovi), Murska sobota 1977.

Achebe, Chinua: The African Trilogy. Things Fall Apart, No Longer at Ease, Arrow of God. Picador, London 1988.

Achebe, Chinua: Mravljišča v savani. Prevedla Jana Cedilnik. Cankarjeva založba (Zbirka XX. stoletje), Ljubljana 1996.

Achebe, Chinua: Home and Exile. Canongate Books, New York; Edinburgh 2003. 
Ahmad, Aijaz: Introduction; Literary Theory and »Third World Literature«; Orientalism and after. V: In Theory: Classes, Nations, Literatures, London and New York 1992, Verso. 1-42, 43-72, 159-220.

Aschroft, Bill; Griffiths, Gareth; Tiffin, Helen: The Empire Writes Back. Theory and practice in post-colonial literatures. Routledge, London 1989, 2003. Aschroft, Bill; Post-Colonial Studies, The Key Concepts. Routledge, London 2002.

Bassnett, Susan/Trivedi, Harish: O kolonijah, kanibalih in jezikih domačinov. V: Literatura 143/144 (letnik XV). Ljubljana 2003. 152-167.

Bhabha, Homi: O mimikriji in človeku: ambivalenca kolonialnega diskurza. V: Literatura 143/144 (letnik XV). Ljubljana 2003. 103-114.

Bhabha, Homi: The Location of Culture, Routledge, London and New York 1994.

Bhabha, Homi: Nation and Narration, Routledge, London and New York 1990.

Boehmer, Elleke: Colonial and Postcolonial Literature. Oxford University Press, Oxford and New York 1995.

Cabral, Amilcar: National liberation and culture. V: Return to the Source: Selected Speeches of Amilcar Cabral. New York 1973, Africa Information Service (Monthly Review). 41-2.

Caroll, David: Chinua Achebe, Twayne, New York 1970.

Cary, Joyce: Mister Johnson. Everyman, London 2001.

Césaire, Aimé: Discourse on Colonialism. Prevedel Joan Pinkham. New York University Press, New York 2000.

Cheyfitz, E.: The Poetics of Imperialism: Translation and Colonization from The Tempest to Tarzan. Oxford University Press, New York in Oxford 1991.

Conrad, Joseph: Srce teme. Prevedel Mart Ogen. Prešernova družba, Ljubljana 1984.

Davidson, Basil: The African Slave Trade. Littel, Brown, Boston 1980. 
Dirlik, Arif: The Postcolonial Aura: Third World Criticism in the Age of Global Capitalism, Critical Inquiry 20 (2), Winter 1994.

Ekwe-Ekwe, Herbert: African Literature in Defence of History: An essay on Chinua Achebe. African Renaissance, Dakar 2003.

Epko, Denis: Towards a Post-Africanism, Textual Practice 9 (1), Spring 1995.

Eze, Emmanuel Chukwudi: Postcolonial African Philosophy. A critical reader. Blackwell Publishers, Oxford 1997.

Fanon, Frantz: Upor prekletih. Prevedel Maks M. Veselko. Cankarjeva založba, Ljubljana 1963.

Fanon, Frantz: Prezreni na svijetu. Predgovor Jean-Paul Sartre. Prevedla Vera Frangeš. Stvarnost, Zagreb 1968.

Fanon, Frantz: Black Skin, White Masks. Prevedel Charles Lam Markmann. Grove Press, New York 1968.

Gates Louis, Henry: Black Literature and Literary Theory. Routledge, New York and London 1990.

Gikandi, Simon: Reading the African Novel. East African Educational Publishers (EAEP), Nairobi, 1987.

Gikandi, Simon: Reading Chinua Achebe. Heinemann, Oxford 1991.

Harasym, Sarah: Gayatri Chakrovorty Spivak: The Post-Colonial Critic: Interviews, Strategies, Dialogues. Routledge, London and New York 1990.

Hegel, Georg Wilhelm Friderich: Naravna sovisnost ali: Geografska podlaga svetovne zgodovine; Delitev svetovne zgodovine. Prevedel Božidar Debenjak. V: Um v zgodovini. Ljubljana 1999, Društvo za teoretsko psihoanalizo (Zbirka Analecta). 143-200.

Igboanusi, Herbert: Igbo English in the Nigerian Novel. Enicrownfit Publishers, Ibadan 2002.

Irele, F. Abiola: The African Imagination. Literature in Africa \& the Black Diaspora. Oxford University Press, Oxford and New York 2001.

Irele, F. Abiola: Critical Perspectives on Chinua Achebe. Lindfors (Three Continents Press), Washington 1978. 
Innes, Lyn in Rooney Caroline: African writing and gender. V: Writing and Africa. Essex 1997, Longman. 193-202.

Isichei, Elizabeth: The Igbo People and the Europeans. Faber, London 1973. James, Adeola: In Their Own Voices: African Women Writers Talk, London 1990.

Jeffs, Nikolai: Od postkolonializma do postsocializma. V: Literatura 143/144 (letnik XV) 2003. 80-102.

Jeffs, Nikolai: Chinua Achebe in politične strategije sodobne afriške literature. V: Mravljišča v savani. Ljubljana 996, Cankarjeva založba. 259-277.

Jeffs, Nikolai: Vojna, mir, avtoriteta. V: Soldatko. Ljubljana 2008, Beletrina. 220-280.

Kane, Cheikh Hamidou: Ambiguous Adventure. Iz francoščine prevedla Katherine Woods. Heinemann, Oxford 1972.

Lindfors, Bernth: Conversations with Chinua Achebe. University Press of Mississippi (Literary conversations series), 1997.

Loomba, Anie: Colonialism / Postcolonialism. Routledge, London and New York 1998.

Omotoso, Kolo: Achebe or Soyinka: A Study in contrasts. Hans Zell Publishers, London 1996.

Ohaeto, Ezenwa: Chinua Achebe, A Biography, James Currey Ltd, Oxford 1997.

Ogungbesan, Kolawole: New West African Literature. Heinemann, London; Ibadan; Nairobi 1979.

Oliver, Roland / Fage, J. D.: A Short History of Africa. Penguin Books, London 1995.

Parker, Andrew: Nationalism and Sexualities, Routledge, London and New York 1992.

Pedler, F. J.: West Africa. Methuen \& Co, London 1951.

Said, Edward W.: Orientalizem. Zahodnjaški pogledi na Orient. Prevedli Lenca Bogovič, Bogdan Lešnik, Igor Zabel. Spremno besedilo Timothy Brennan. Studia Humanitatis, Ljubljana 1996. 
Segun, Mabel: The Surrender and Other Stories. Longman African Writers, Essex 1995.

Senghor, Léopold Sédar: Senghor. Prevedel in spremno besedilo napisal Aleš Berger. Mladinska knjiga (Zbirka Lirika), Ljubljana 1975.

Wauthier, Claude: The Literature \& Thought of Modern Africa. Heinemann, London; Nairobi; Ibadan; Lusaka 1978.

Wilkinson, Jane: Talking with African Writers. Interviews with African Poets, Playwrights \& Novelists. Heinemann Educational Books, London 1992. 47-59.

Wiredu, Kwesi: Philosophy and an African culture. Cambridge University Press, Cambridge 1980.

Virk, Tomo: Moderne metode literarne vede in njihove filozofsko teoretske osnove. Filozofska fakulteta: Oddelek za primerjalno književnost in literarno teorijo, Ljubljana 1999. 


\section{CHINUA ACHEBE'S NOVEL THINGS FALL APART AS A RESPONSE TO THE NEGATIVE PORTRAYAL OF AFRICANS}

Keywords: decolonization, other, postcolonial literature, essentialism

\section{Abstract}

Marx's adage »They cannot represent themselves, they must be represented " (»Sie können sich nicht vertreten, sie müssen vertreten werden«) in "The 18th Brumaire of Louis Napoleon, "which Edward Said in turn quoted at the beginning of his book Orientalism, still held for colonial Africa up to 1952. At the time, a class of Nigerian students at Ibadan University, including Chinua Achebe, were discussing Joyce Cary's latest book Mister Johnson. Cary's work, together with Joseph Conrad's Heart of Darkness, epitomized a tradition more than a century long of negative portrayals of Africans. The slave trade from the sixteenth to the nineteenth century spawned a »literature of degradation « in relation to Africa, which represented Africans as objects devoid of any personality, removed from the world of reason or time. Essentialized texts of an invented Other, which travelers would read before encountering the unknown, the threatening, and the remote, generally acquired a greater credibility than the description of an actual reality. In time, the dominant narrative gave rise to a tradition, or what Foucault terms a »discourse.«

Given that Achebe's first novel, whose publication sparked an incident at Ibadan University in 1952, was in itself an act of rebellion and a form of rejoinder to the colonial representation of Africans, it is understandable that the absence of personality, historicity, and understanding are integral to his novels. Writing an "African " novel or »anti-novel « meant transcending the »objectivity« of colonial discourse and drawing into one's consciousness the history and culture of the Igbo people (primarily from southeast Nigeria), although the description of pre-colonial society at the moment of its first contact with the white man does not imply a nostalgic return to the past, as is notable for instance in the négritude movement. The potency of 
Achebe's novel lies in the fact that by invoking Igbo culture he has turned the colonial perception of Africans as inferior on its head, although the anti-colonial dialectics are intimately bound up with his representation of the African woman. Achebe's women are marginalized just as in Fanon's work - the novel Things Fall Apart is in some ways a response to Fanon's theoretical work The Wretched of the Earth. Women in Achebe's trilogy Things Fall Apart, No Longer at Ease, and Arrow of God have above all a symbolic and metaphorical role, being represented as the mother of the land, whereas men are individual figures. This representation of women is linked to the fact that the first two novels, which were written before the independence of Nigeria in 1960, develop the idea of the national struggle for liberation, which reaffirms the humanity and manhood of the colonized, whereas colonialism only assigned to Africans the attributes of children or at best those of women. In Achebe's favor, one can say that Okunkwo, as the reincarnation of the social ideal of manhood, is continually fighting with the basic tenet of both the preceding (i.e., his father's) and future (i.e., his son's) generation, and that of women, no less, which is only fully realized in Achebe's last novel The Anthills of the Savanna. Many African women writers, including Flora Mwapa, Ama Ata Aidoo, Buchi Emecheta, Mariama Bâ, and Mabel Segun, later »corrected « Achebe’s representation of women. 